http://jmscr.igmpublication.org/home/

ISSN (e)-2347-176x ISSN (p) 2455-0450

crossref DOI: https://dx.doi.org/10.18535/jmscr/v8i4.72

\title{
A Comparative Study of Results of Canal Wall Up \& Canal Wall down Mastoidectomy as a Surgical Treatment for Cholesteatoma
}

\author{
Authors \\ Dr Shikha Bhatt ${ }^{1}$, Dr Vaibhav Kuchhal ${ }^{*}$, Dr Shahzad Ahmad ${ }^{3}$, \\ Dr Varun Rawat ${ }^{4}$, Dr Ravi Baniya ${ }^{5}$ \\ ${ }^{1,4,5}$ PG Resident 3rd yr ENT Dept GMC Haldwani Uttarakhand \\ ${ }^{2}$ Professor and Head of ENT Dept GMC Haldwani Uttarakhand \\ ${ }^{3}$ Associate Professor ENT Dept GMC Haldwani Uttarakhand \\ *Corresponding Author \\ Dr Vaibhav Kuchhal
}

\begin{abstract}
Background: The aim of this study is to compare the results of canal wall up and canal wall down mastoidectomy as a surgical treatment for cholesteatoma.

Method: This study was a comparative prospective study carried out in the department of otorhinolaryngology.

Results \& Conclusion: Hearing results in CWU mastoidectomy were better than in CWD mastoidectomy. With canal wall down technique, the rate of developing complications (persistent ear discharge) was significantly higher when compared with those in canal wall up technique. Other complications ie; perichondritis, wound dehiscence, facial nerve palsy were nil in either group. Recurrence or residual disease was not reported in our cases which may be due to short period of follow up (3 months).

Keywords: Chronic Ototis Media, Pure Tone Audiometry.
\end{abstract}

\section{Introduction}

A unifying definition of the term "cholesteatoma" is a three dimensional epidermal \& connective tissue structure usually in form of a sac \& frequently confining to the architecture of the various spaces of the middle ear, attic, \& mastoid. This structure has the capacity for progressive \& independent growth at the expense of underlying bone \& has a tendency to of recurrence after removal $^{1}$ Three factors appear to be involved in the process of bony resorption: (a) mechanical, related to pressure generated by the expansion of cholesteatoma (b) biochemical, due to bacterial elements (endotoxins), products of the host's granulation tissue (collagenase, acid hydrolases), and substances related to the cholesteatoma itself (growth factors, cytokines); and (c) cellular, predominantly induced by osteoclastic activity. ${ }^{2}$

\section{Aim}

The aim of the study is to compare the results of canal wall up and canal wall down mastoidectomy as a surgical treatment for cholesteatoma performed in the department of otorhinolaryngology. The outcome compared in terms of: 
- Improvement of hearing

- Complications, if any

\section{Materials and methods}

This study is a comparative prospective study carried out on 70 patients in total having Chronic Otits Media (active squamosal type) presenting in the OPD in the department of Otorhinolaryngology.

The patients categorised into 2 groups of 35 patients each:

Patients in Group A undergone CWU mastoidectomy.

Patients in Group B undergone CWD mastoidectomy.

CWD mastoidectomy done by giving William Wilde's incision. Temporalis fascia graft harvested. Periosteal flap elevated \& used to obliterate mastoid cavity later. Meatotomy done. Tympanomeatal flap elevated. Mac ewans triangle identified. antrostomy done. facial bridge broken $\&$ facial ridge lowered. Cholesteatoma removed from all involved areas. Ossicular reconstruction done as per intraoperative status of ossicles. Temporalis facia graft placed by underlay technique. Meatoplasty done.

CWU mastoidectomy done by giving William Wilde's incision. Temporalis fascia graft harvested. periosteal flap elevated. meatotomy done. Mac ewans triangle identified. antrostomy done. cholesteatoma removed from all involved areas. ossicular reconstruction done as per intraoperative ossicular status. temporalis facia graft placed by underlay technique.

\section{Inclusion Criteria}

- All patients with cholesteatoma

\section{Exclusion Criteria}

- Patient/guardian refusal for consent

- All patients with chronic otitis media inactive squamous type

- Congenital cholesteatoma
- Patients with recurrent or residual cholesteatoma (previously operated cases)

- Patients with sensorineural hearing loss

- Patients unfit for general anaesthesia

\section{Results}

1. Comparison of mean PTA (pre-operative and post operative) among CWD group shows that mean PTA was higher pre operatively but it decreased at 6 weeks and further at 12 weeks and but only the difference at 12 weeks was found to be statistically significant.

\section{Figure: 1}

\begin{tabular}{|lccc|}
\hline PTA & \multicolumn{2}{c}{ CWD } & p Value \\
& Mean & SD & \\
\hline Pre op & 48.85 & 7.81 & 0.06 \\
\cline { 1 - 3 } at 6 weak & 47.35 & 8.04 & \\
\hline Pre op & 48.85 & 7.81 & 0.007 \\
\hline at 12 weak & 43.77 & 10.86 & \\
\hline
\end{tabular}

2.Comparison of mean PTA pre-operative and post operative among CWU group shows that mean PTA was higher pre operatively but it decreased at 6 weeks and further decreased at 12 weeks; this was found to be statistically significant.

Figure: 2

\begin{tabular}{|l|c|c|c|}
\hline \multirow{2}{*}{ PTA } & \multicolumn{2}{|c|}{ CWU } & \multirow{2}{*}{ p Value } \\
\cline { 2 - 3 } & Mean & SD & \\
\hline Pre op & 52.93 & 6.41 & 0.001 \\
\hline at 6 weak & 47.97 & 6.38 & \\
\hline Pre op & 52.93 & 6.41 & 0.001 \\
\hline at 12 weak & 41.27 & 8.66 & \\
\hline
\end{tabular}

\section{Comparison of PTA among two surgery group}

Shows that mean PTA was significantly higher in CWU group as compared to CWD. PTA at 6 weeks post op was higher in CWU group but at 12 weeks it was higher in CWD group but both this difference was not found to be statistically significant.

Figure: 3

\begin{tabular}{|llllll|}
\hline \multirow{2}{*}{ PTA } & \multicolumn{2}{l}{ Surgery } & & & p \\
& CWD & & CWU & & Value \\
& Mean & SD & Mean & SD & \\
\hline Pre op & 48.85 & 7.81 & 52.93 & 6.41 & 0.02 \\
\hline at 6 weak & 47.35 & 8.04 & 47.97 & 6.38 & 0.72 \\
\hline at 12 weak & 43.77 & 10.86 & 41.27 & 8.66 & 0.29 \\
\hline
\end{tabular}




\section{JMSCR Vol||08||Issue||04||Page 387-393||April}

4. Hearing results at postoperative (6 wks)

Hearing improvement is more in CWU group (85.71\%) comparative to CWD group (62.85\%) at 6 wk postoperative PTA

Figure: 4

\begin{tabular}{|lcccc|}
\hline Hearing improvement (db) & CWU & \% & CWD & \% \\
\hline$<10$ & 25 & 71.4 & 20 & 57.1 \\
\hline $\mathbf{1 0}$ to 20 & 5 & 14.2 & 2 & 5.71 \\
\hline $\mathbf{2 0}$ to 30 & 0 & 0 & 0 & 0 \\
\hline Total & 30 & 85.71 & 22 & 62.85 \\
\hline
\end{tabular}

5. Hearing improvement at postoperative $(6 \mathrm{wks})$

Figure: 5

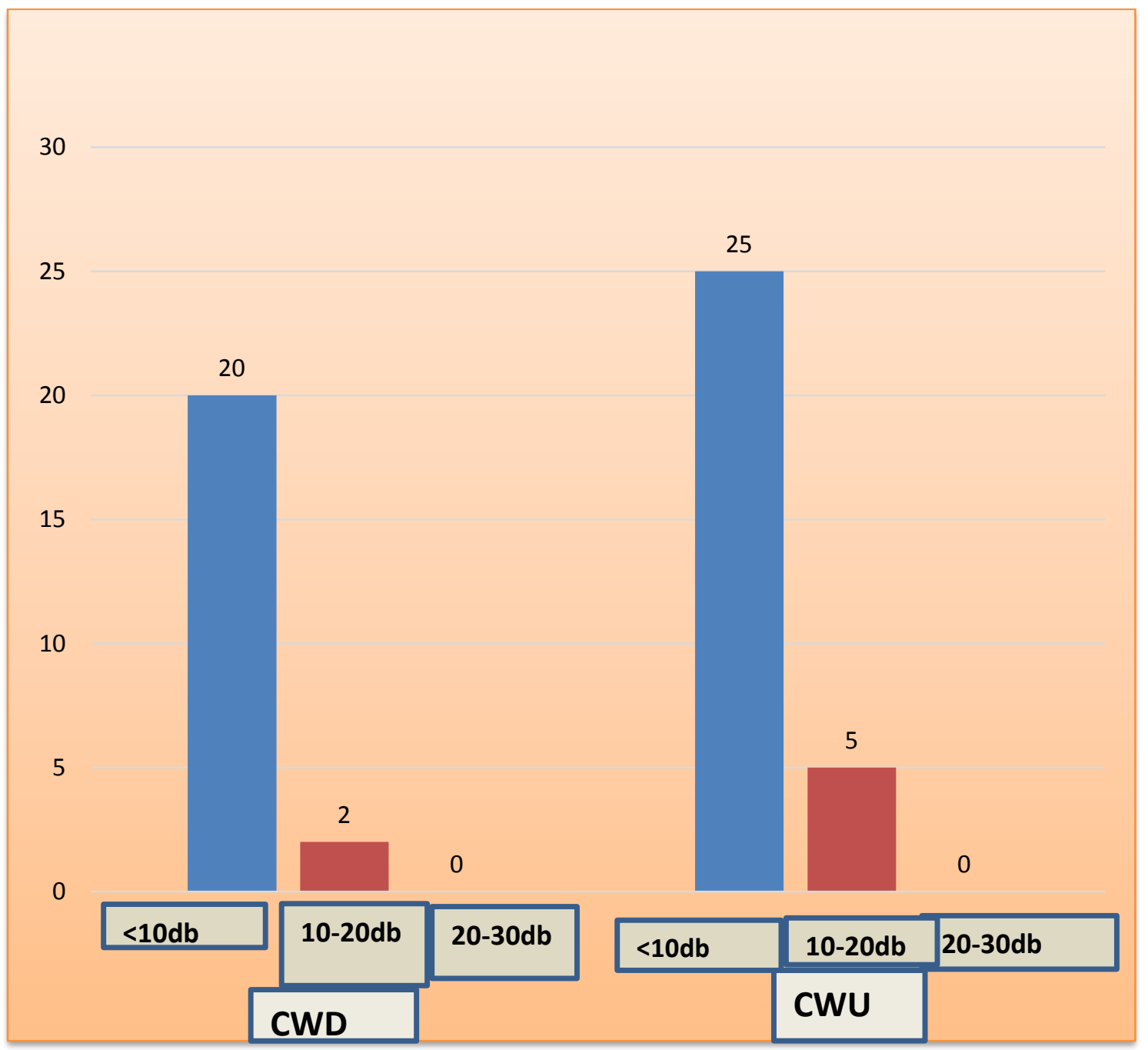

6. Hearing results at postoperative ( $12 \mathrm{wks})$

Hearing improvement is more in CWU group (88.57 \%) comparative to CWD group (65.71\%) in postoperative 12 wks PTA

Figure: 6

\begin{tabular}{|l|c|c|c|c|}
\hline Hearing improvement (db) & CWU & \% & CWD & \% \\
\hline$<\mathbf{1 0}$ & 12 & 34.28 & 10 & 28.57 \\
\hline $\mathbf{1 0}$ to 20 & 11 & 31.42 & 10 & 28.57 \\
\hline $\mathbf{2 0}$ to 30 & 8 & 22.85 & 3 & 8.57 \\
\hline Total & 31 & 88.57 & 23 & 65.71 \\
\hline
\end{tabular}


7. Hearing improvement at postoperative (12 wks)

Figure: 7

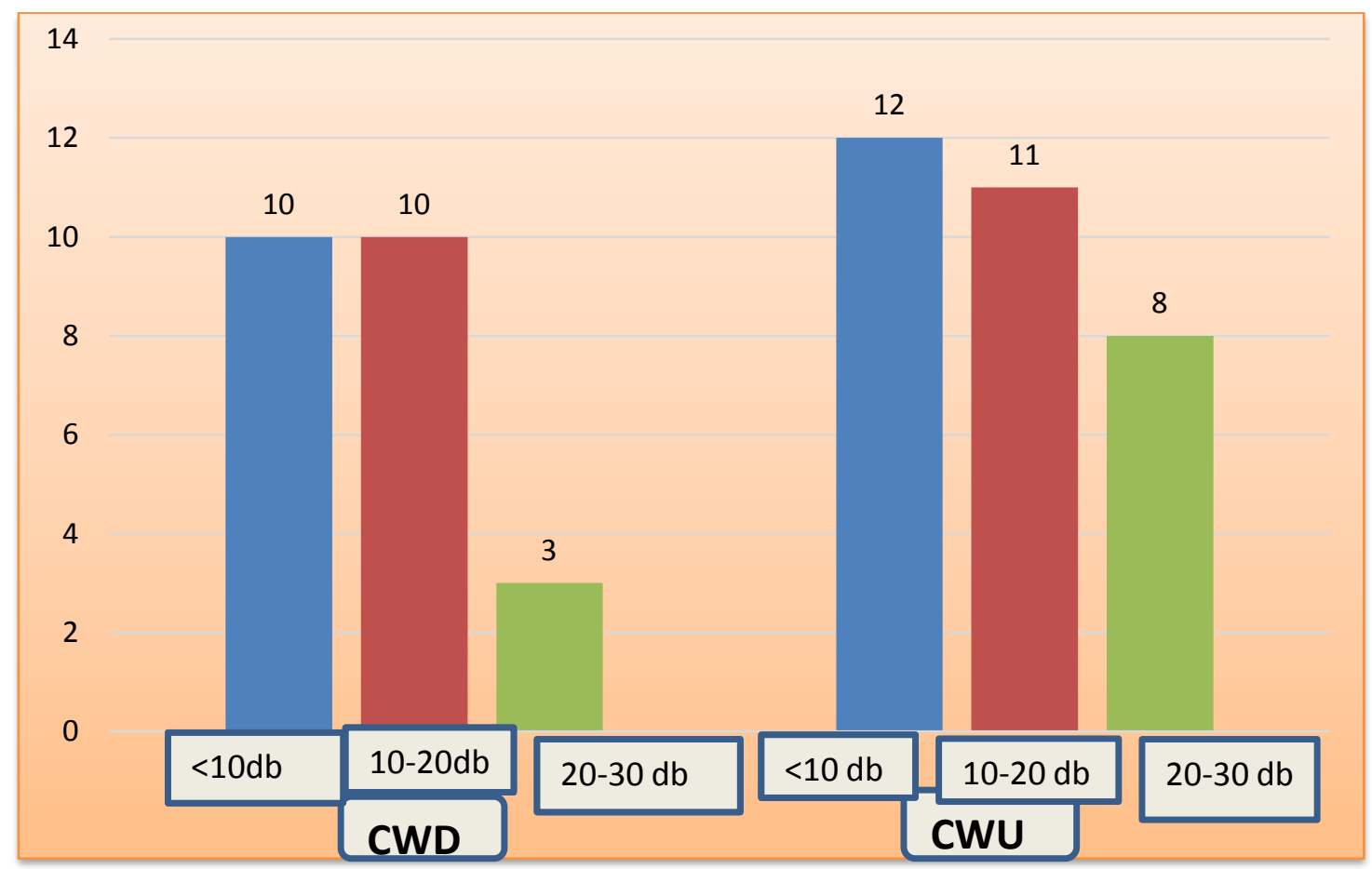

8. Comparison of complication among two surgery group

Shows that ear discharge post operatively was seen in $20 \%$ of patient undergoing CWD procedure while it was seen in $14.3 \%$ of patient undergoing CWU procedure. This difference was not found to be statistically significant.

Figure: 8

\begin{tabular}{|lcccccc|}
\hline \multirow{2}{*}{ Surgery } & \multicolumn{4}{c}{ Complication } & Total & p Value \\
& \multicolumn{2}{c}{ Ear Discharge } & \multicolumn{2}{c}{ None } & & \\
\cline { 2 - 6 } & No. & $\%$ & No & $\%$ & & \\
\hline CWD & 7 & 20.0 & 28 & 80.0 & 35 & 0.53 \\
\hline CWU & 5 & 14.3 & 30 & 85.7 & 35 & \\
\hline Total & 12 & 17.1 & 58 & 82.9 & 70 & \\
\hline
\end{tabular}

\section{Complication among two surgery group}

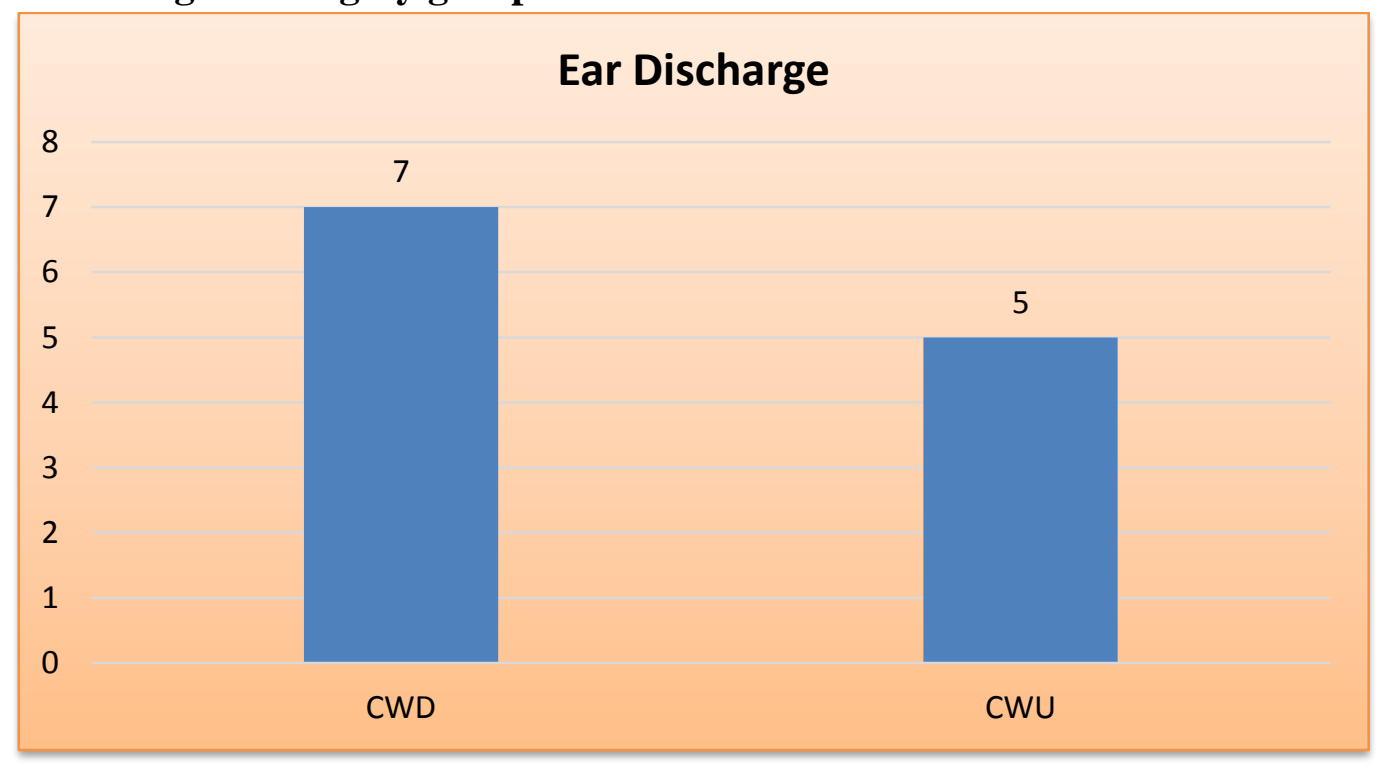




\section{Discussion}

A great deal of debate exists as to the most appropriate surgical technique for the management of cholesteatoma. This study was undertaken with the objective of comparing the results of canal wall up \& canal wall down mastoidectomy as an surgical treatment for cholesteatoma.

\section{Hearing improvement}

Results of group 1 patients (canal wall up mastoidectomy)

At 6 wks postoperative period $(85.71 \%)$ patients $\&$ at 12 wks postoperatively $(88.57 \%)$ patients had hearing improvement. (2.85\%) patients had same hearing \& $(8.57 \%)$ patients had deterioration of hearing. With regards to post operative improvement of hearing $\mathrm{p}$ value is found to be .001 at ( 6 wks \& 12 wks) which is $<0.05$ and is found to be significant.

In CWU group at postoperative 6 wks 25 patients (71.4\%) had hearing improvement less than 10 db.5 patients (14.2\%) had hearing improvement 10-20 db. At postoperative 12 wks , 12 patients $(34.28 \%)$ had hearing improvement less than 10 $\mathrm{db} ; 11$ patients $(31.42 \%)$ had hearing improvement $10-20 \mathrm{db} \& 8$ patients $(22.85 \%)$ had hearing improvement 20-30 db. Average hearing gain in CWU mastoidectomy at $6 \mathrm{wks}$ is $6.4 \mathrm{db} \&$ at 12 wks is $24.49 \mathrm{db}$.

\section{Results of group 2 patients (canal wall down mastoidectomy)}

At 6 wks postoperative period $(62.85 \%)$ patients $\&$ at 12 wks postoperatively $(65.71) \%$ patients had hearing improvement $(2.85 \%)$ patients had same hearing \& (31.42\%) \% patients had deterioration of hearing. Mean PTA was higher pre operatively but it decreased at 6 weeks and further at 12 weeks; but only the difference at 12 weeks was found to be statistically significant. $p$ value at 6 wks 0.06 statistically not significant; $p$ value at 12 wks 0.007 which is $<0.05$ and was found to be statistically significant . CWD group at postoperative 6 wks 20 patients $(57.1 \%)$ had hearing improvement less than $10 \mathrm{db} .2$ patients (5.71\%) had hearing improvement 10-20 db. At postoperative 12 wks 10 patients $(28.57 \%)$ had hearing improvement less than $10 \mathrm{db} .10$ patients (28.57\%) had hearing improvement 10-20 db.3 patients $(8.57 \%)$ had hearing improvement $20-30$ $\mathrm{db}$. Average hearing gain in CWD mastoidectomy at 6 wks was $6.0 \mathrm{db} \&$ at 12 wks was $11.25 \mathrm{db}$.

Hearing gain in CWU mastoidectomy and CWD mastoidectomy at 6 wks was $6.4 \mathrm{~dB}$ and $6.0 \mathrm{~dB}$, at 12 wks was $24.49 \mathrm{~dB}$ and $11.25 \mathrm{~dB}$, thus concluding that the hearing results in CWU mastoidectomy is better than in CWD mastoidectomy.

By Chi-Square test,

With regards to post operative improvement of hearing in both groups of patients, $p$ value is found to be $<0.05$ and is found to be significant; proving that canal wall up mastoidectomy is better than canal wall down procedure.

Similar to our results Tos et $\mathbf{a l}^{3}$ prefer canal wall up mastoidectomy as hearing threshold are worse after canal wall down mastoidectomy.

Similar results to our study were present in study done by Bhat S. et al . ${ }^{4}$ They conducted study \& compared the outcomes of hearing gain in canal wall up versus canal wall down mastoidectomy surgeries. Hearing gain was better in canal wall up mastoidectomy $(18.36 \mathrm{~dB})$ than canal wall down mastoidectomy surgeries.

Hearing results in CWU mastoidectomy were better in study done by Kalital S et $\mathbf{a l}^{5}$; which is comparative to our study. They conducted prospective comparative clinical study; In the preoperative period, patients with $\mathrm{ABG} \leq 30 \mathrm{~dB}$ was $3.33 \%$ in CWD group and $6.67 \%$ in the ICW group; in 3 months postoperative period, it was $3.33 \%$ (CWD) and 20\% (ICW); for 6 months postoperative period, it was $14.81 \%$ (CWD) and $34.48 \%$ (ICW). From these observations, it was evident that there was a shift of the $A B G$ of patients towards the better hearing range, ICW $>$ CWD.

Osborn et al $^{6}$ concluded that ICW patients had better postoperative hearing as that of our study (median AB gap, $38 \mathrm{~dB}$ vs $51 \mathrm{~dB}, \mathrm{P}=.004$ ) and greater hearing improvement (median hearing 
gain, $7 \mathrm{~dB}$ vs $0 \mathrm{~dB}, \mathrm{P}=.004)$ than the $\mathrm{CWD}$ group;

Varshney et al $^{7}$ compared the hearing results by ICWM versus CWDM. Hearing gain in ICWM and CWDM at 3 months was $19.37 \mathrm{~dB}$ and $11 \mathrm{~dB}$, at 6 months was $21.91 \mathrm{~dB}$ and $13.61 \mathrm{~dB}$, thus concluding that the hearing results in ICWM is better than in CWDM. Results of this study are comparable to ours.

Toner J G et $\mathbf{a l}^{8}$ published their comparison of patients who had CWU, CWD with reconstruction and CWD surgery with follow up of between 8 and 12 years. They found that the hearing benefit at one year (pure tone average (PTA) air conduction (AC) threshold) was greater in the CWU group. Our results also showed similar results. It may be due to CWD mastoidectomy changes the architecture of the ear canal which results in diminished hearing to some degree as a result of this change of architecture.

\section{Complications}

In the CWD group postoperatively 7 out of 35 patients (20\%) had ear discharge problem while In the CWU group postoperatively 5 out of 35 patients $(14.8 \%)$ had ear discharge problem .With regards complications in both groups of patients, $p$ value is found to be 0.53 which is $>0.05$ and is found to be not significant.

Our results showed that with canal wall down technique, the rate of developing complications (persistent ear discharge) was significantly higher when compared with those in canal wall up technique.

Similar findings were observed by Kos MI et al', who reported that complication rate (ear discharge) was higher with canal wall down surgery years after surgery, cavities were found to be dry and self-cleaning in $95 \%$ of the cases, and still humid, with otorrhea, in $5 \%$ of the cases.

Similar to our study Hulka and McElveen ${ }^{10}$ in their study reported significantly higher rate of complications (ear discharge) after canal wall down procedure.
Sadé et al $^{\mathbf{1 1}}$ reported findings of persistent ear discharge after canal wall down technique which is comparable to our results.

Gantz BJ et $\mathbf{a l}^{\mathbf{1 2}}$ in their study of 30 cases, reported the same higher rates of complications after canal wall down surgeries as that of our study.

Mustafa Sadaf Raffat et al ${ }^{\mathbf{1 3}}$ evaluated a total of sixty patients of chronic otitis media with cholesteatoma. Complications rates (Persistent ear discharge) was higher in CWD patients; which is comparable to our study.

Similar to our study Ueda $\mathbf{H}$ et $\mathbf{a l}^{\mathbf{1 4}}$ in their study reported that postoperative complications, such as erosion of the mastoid cavity, otorrhea occurred more frequently in the canal wall down mastoidectomy group. They concluded that their strategy for paediatric cholesteatoma in the future is to use canal wall up mastoidectomy when possible.

Harkness $\mathbf{P}$ et $\mathbf{a l}^{\mathbf{1 5}}$. In their study suggested that there were a statistically significant greater number of "wet" ears with canal wall down than with canal wall up mastoidectomies; which is comparable to our study

Rambo J H et al ${ }^{\mathbf{1 6}}$ in their study suggested that buried mucosa leading to cystic formation is the principal factor responsible for the wide variation in healing, even though all chronic disease has been removed in CWD mastoidectomies leading to wet ears.

\section{Conclusion}

Hearing gain in CWU mastoidectomy and CWD mastoidectomy at 6 wks was $6.4 \mathrm{~dB}$ and $6.0 \mathrm{~dB}$, at 12 wks was $24.49 \mathrm{~dB}$ and $11.25 \mathrm{~dB}$ respectively, thus concluding that the hearing results in CWU mastoidectomy is better than in CWD mastoidectomy.

In the CWD group postoperatively 7 out of 35 patients $(20 \%)$ had ear discharge problem while In the CWU group postoperatively 5 out of 35 patients $(14.8 \%)$ had ear discharge problem. In canal wall down technique, the rate of developing complications (persistent ear discharge) was 
significantly higher when compared with those in canal wall up technique. Other complications ie; perichondritis, wound dehiscence, facial nerve palsy were nil in either group.

Recurrence or residual disease was not reported in our cases which may be due to short period of follow up (3 months).

\section{References}

1. Harold L \& Tony W: Diseases of the ear: a diseases ear, $6^{\text {th }}$ edn; $\mathrm{p} 386$.

2. Telian AS, Schmalbach CE. Chronic otitis media. In:Snow Jr JB, Ballenger JJ, eds. Ballenger's Otorhinolaryngology Head and Neck surgery, $16^{\text {th }}$ edn. Hamilton, Ontario: BC Decker,2003;PP:261

3. Tos M, Lasu T. Hearinng after surgery for cholesteatoma using various techniques. Auris Nasus Larynx 1989;16(2):61-73

4. Bhat PS, Gandhi G, A comparative study of hearing outcomes in canal wall up versus canal wall down mastoidectomy in our experience. Int $\mathbf{J}$ Otorhinolaryngol Head Neck Surg 2019;5:472-5.

5. Kalita S, Uddin S, Patar $M$ et al. A comparative study on the hearing outcome in canal wall down and intact canal wall mastoidectomy in chronic suppurative otitis media with special reference to atticoantral disease. International Journal of Research and Review. 2018; 5(6):94103

6. Osborn AJ, Papsin BC, James AL. Clinical indications for canal wall-down mastoidectomy in a pediatric population. Otolaryngology--Head and Neck Surgery. 2012 Aug 1;147(2):316-22.

7. Varshney PK, Gupta R. Canal wall up versus canal wall down procedure: Comparative evaluation. Ind $\mathrm{J}$ Otol. 2009;15:20-2.

8. Toner JG, Smyth GD. Surgical treatment of cholesteatoma: a comparison of three techniques. Am J Otol. 1990; 11(4): 2479 .
9. Kos MI, Castrillon R, Montandon P, Guyot J-P. Anatomic and functional longterm results of canal wall-down mastoidectomy. Ann Otol Rhinol Laryngol. 2004; 113(11):872-6.

10. Hulka.GF and McElveen JT Jr: A randomised blinded study of canal wall up versus canal wall down mastoidectomy determining the differences in viewing middle ear anatomy and pathology. Am J Otol 1998, 19(5):574-578

11. Sadé J: Surgical planning of the treatment of cholesteatoma and post-operative follow-up. Ann Otol Rhinol Laryngol 2000; 109(4):372-6.

12. Gantz BJ, Wilkinson EP, Hansen MR. Canal Wall Reconstruction Tympanomastoidectomy with Mastoid Obliteration. Laryngoscope. 2005; 115(10):1734-40.

13. Mustafa SR. Comparison of Efficacy of Canal Wall Up Mastoidectomy with Canal Wall Down Mastoidectomy in Surgical Management of Otitis Media. JIMDC. 2017; 6(2):78-82.

14. Ueda H, Nakashima T, Nakata S. Surgical Strategy for cholesteatoma in children. Auris Nasus Larynx 2001 Apr : 28(2) : 125-9.

15. Harkness P, Brown PM, Fowler SM, Grant HR, Ryan RM, Topham JH. Mastoidectomy audit: results of the Royal College of Surgeons of England comparative audit of ENT surgery. Clin Otolaryngol. 1995;20:89-94.

16. Rambo JH. Mastoid surgery: effect of retained mucosa on healing. Ann Otol Rhinol Laryngol. 1979;88:701-707. 